Bond University

Research Repository

\title{
Lifetime prevalence of non-melanoma and melanoma skin cancer in Australian recreational and competitive surfers
}

Climstein, Mike; Furness, James; Hing, Wayne; Walsh, Joe

Published in:

Photodermatology Photoimmunology and Photomedicine

DOI:

$10.1111 /$ phpp. 12247

Licence:

Unspecified

Link to output in Bond University research repository.

Recommended citation(APA):

Climstein, M., Furness, J., Hing, W., \& Walsh, J. (2016). Lifetime prevalence of non-melanoma and melanoma skin cancer in Australian recreational and competitive surfers. Photodermatology Photoimmunology and Photomedicine, 32(4), 207-213. https://doi.org/10.1111/phpp.12247

\section{General rights}

Copyright and moral rights for the publications made accessible in the public portal are retained by the authors and/or other copyright owners and it is a condition of accessing publications that users recognise and abide by the legal requirements associated with these rights.

For more information, or if you believe that this document breaches copyright, please contact the Bond University research repository coordinator. 
Lifetime prevalence of non-melanoma and melanoma skin cancer in Australian

2 recreational and competitive surfers

3 


\section{$4 \quad \underline{\text { Abstract }}$}

\section{Background/purpose}

6 Surfing is one of the most popular outdoor aquatic activities in Australia with an estimated

$7 \quad 2.7$ million recreational surfers however, Australia has long been recognized as having the

8 highest incidence of melanoma in the world, and it is the most common type of cancer in

9 young Australians. The aim of this study was to investigate the lifetime prevalence of non-

10 melanoma (basal cell carcinoma (BCC), squamous cell carcinoma (SCC)), and melanoma

11 skin cancers in Australian recreational and competitive surfers.

\section{Methods}

13 Australian surfers were invited to complete an online surveillance survey to determine the

14 lifetime prevalence of non-melanoma and melanoma skin cancers.

\section{Results}

16 A total 1,348 surfers (56.9\% recreational) participated in this study, of which 184 surfers

17 reported a skin cancer (competitive $n=96$, recreational $n=87$ ). Of non-melanoma and

18 melanoma cancers reported, BCC was the most common (6.8\%), followed by melanoma

$19(1.4 \%)$ and SCC $(0.6 \%)$. The relative risk was higher $(\mathrm{p}<0.001)$ in competitive versus

20 recreational surfers (OR 1.74 (CI 1.28-2.31)). There was a higher $(\mathrm{p}<0.05)$ number of skin

21 cancers reported on the face (23.5\%), back (16.4\%) and arms (12.4\%). There were significant trends $(\mathrm{p}<0.001)$ in reported skin cancers between competitive and recreational surfers, as well as significantly $(\mathrm{p}<0.001)$ more skin cancers reported in males $(14.6 \%)$ than

24 females (9.4\%).

\section{Conclusion}


26 Based upon these findings, individuals who surf are advised to regularly utilize sun protection

27 strategies (avoid peak ultra violet radiation (10am-3pm), rashvest, hat and sunscreen) and

28 primary care physicians are recommended to regularly screen their patients who surf.

29

30 Keywords: physical activity; public health; questionnaire survey; sun exposure; skin

31 neoplasms; ultraviolet radiation

32

33 


\section{Introduction}

Surfing is one of the most popular outdoor aquatic activities in Australia with an estimated 2.7 million recreational surfers (1). As a result the expected risk of skin cancer in surfers due to long periods of exposure to ultraviolet radiation (UVR) (2), wearing less clothing and reflection from water is of great concern. According to the Cancer Council, nearly one third of all Australians had a skin cancer, making it the most common type of cancer in Australians (3). Non-melanoma skin cancers (NMSC) were the most prevalent with over 750,000 treated each year. Australia has also been recognized as having the highest incidence of melanoma skin cancer (MSC) in the world (4-6), and it is the most common cancer in Australians aged 15 to 29 years (7), although this has recently been challenged (8). Melanoma is also the third most common form of skin cancer, the mechanism of which is attributed to sunlight exposure, particularly UVR within the 250 to $400 \mathrm{~nm}$ wavelength $(9,10)$. It is estimated in 2015 there will be an estimated 938,000 treatments related to skin cancer in Australia, reportedly costing the medical benefits scheme $\$ 703$ million for diagnosis, treatment and pathology (11). A recent report on the epidemiological incidence of keratinocyte skin cancer revealed basal cell carcinoma (BCC) was the most common type of skin cancer in the Australian population followed by squamous cell carcinoma (SCC) (12), the report emphasized UVR exposure is of critical importance in Australian as a mechanism for the development of skin cancer. Despite the popularity of surfing there is very limited research (13) available on the prevalence of skin cancers in surfers. Dozier and Wagner (12) reported the results of a free skin cancer screening conducted by dermatologists in Texas (USA) surfers $(n=49)$. The majority $(73.4 \%)$ of the surfers screened were identified as having atypical moles (36.7\%), actinic keratosis (40.8\%) and BCCs $(16.3 \%)$. Significance $(\mathrm{p}<0.47)$ was only identified with regard to BCCs in the surfers as opposed to a self-selected general population (16.3\% versus 3.2\%, respectively). There were no lesions identified that were suggestive of SCCs or melanomas. The purpose 
59 of this study was to investigate the lifetime prevalence of non-melanoma and melanoma skin cancers in recreational and competitive surfers in Australia.

\section{Methods}

63

64

65

66

\section{Sample}

68

69

\section{Survey}

\section{Study design}

This research utilized a commercially available, customizable cloud-based survey in a crosssectional observational study design.

Given the wide geographic distribution of surfing in Australia, an on-line survey was developed to allow for national data collection on surfing injuries (14) and determine the lifetime prevalence of non-melanoma and melanoma skin cancers in recreational and competitive surfers. We defined lifetime prevalence as the proportion of the population who, at some point in their lifetime up to the time of this survey, has ever had a melanoma (MSC) or non-melanoma skin cancer (NMSC). Media (broadcast, print and radio) promotion and direct contact with national surfing organizations and surfing clubs $(n=103)$ was utilized to promote the study to all individuals who were currently surfing either recreationally or competitively in Australia. Ethics approval for this study was granted by Bond University Human Research Ethics committee (RO1540).

The survey consisted of two primary sections. Section 1 contained questions that pertained to participants physiological demographics (such as age, height, mass) and their surfing specific 
82 demographics (board type) and surfing exposure (average hours per week and weeks per

83

84

85 year for the previous year). Additionally, we inquired if the participants surfed during peak UVR which is recognized as $10 \mathrm{am}$ to $3 \mathrm{pm}$, inclusive $(15,16)$. We also queried the participants surf status (recreational or competitive) and if the latter whether it was for their local club, international or the World Championship Tour. Section 2 pertained to surfing injuries (14) (acute and chronic) and included questions pertaining to the lifetime prevalence of non-melanoma and melanoma skin cancers. Participants were instructed to report only NMSCs and MSCs by type and location that have only been diagnosed and/or treated by either a general practitioner (GP) or dermatologist. This question specified that diagnosis needed to be confirmed by tissue biopsy, however participants were not required to upload either medical reports of diagnosed skin cancers or associated pathology reports. As most of the participants would be unaware of their Fitzpatrick skin phototype (17) we simplified skin types to the following; fair, medium, olive, brown and black (18).

Survey questions consisted of array, single choice, multiple choice, list dropdown, numerical input and short answer free text. Filters (where appropriate) were utilized to ensure participants provided electronic informed consent (individuals under the age of 18 years were required to have parental or guardian supervision whilst completing the survey), met entry criteria, expedite completion of the survey and help ensure responses were within logical limits. Additionally, participants were informed they could only complete one survey per participant and the online survey mechanism allowed each participant to only complete the survey once. All participants were required to provide informed consent electronically to enable access to the survey which was active for six months.

\section{Statistical analysis}


106 Data normality was assessed by investigating kurtosis, skewness, Q-Q plots, as well as the 107 Kolmogorov-Smirnov (KS) test with Lilliefors significance correction. Heteroscedasticity 108 was assessed using Levene’s test. Statistical analyses were completed using the IBM 109 Statistical Package for the Social Sciences (SPSS, version 22) and included demographics 110 (mean $\pm \mathrm{SD}$ ), correlations, t-tests and chi-square tests to determine significance of differences 111 between groups, alpha was set at $\mathrm{p}<0.05$ a priori.

113 Results

\section{Sample characteristics}

115 Table 1 depicts the physiological and surfing demographics of all participants. A total of 1,348 116 surfers completed the survey, the majority of which were male (91.3\%) and surfing 117 recreationally (56.9\%). The overall mean age of participants was 35.8 years (range 11-70) with competitive surfers $(\mathrm{n}=581,43.1 \%)$ significantly $(\mathrm{p}<0.05)$ older $(+3.9 \%)$ and slightly shorter (-.05\%) than recreational surfers. With regard to surfing demographics competitive surfers reported surfing significantly $(\mathrm{p}<0.001)$ more hours per week $(+37.2 \%)$, weeks per year $(+13.4 \%)$ and total hours per year (+43.8\%). There was no difference ( $\mathrm{p}>0.05)$ with regard to surfing exposure between genders. The majority of surfers rode short boards (82\%), followed by longboards (10.9\%) and mini-mals (7.1\%) 
128 A total of 184 of the survey participants (13.6\%) reported being diagnosed and/or treated for a

129 NMSC and/or MSC (Figure 1), there were a greater number of skin cancers reported in competitive (Table 2) than recreational surfers $(\mathrm{p}<0.05)$. Competitive surfers had reported

131 proportionally more skin cancers than recreational surfers (16.5\% and $11.4 \%$, respectively).

132 The relative risk of developing a skin cancer was significantly $(\mathrm{p}<0.001)$ higher in competitive versus recreational surfers (odds ratio 1.74 (CI 1.28-2.31)). An additional 37 participants (2.7\%) reported having a skin cancer however, were unable to recall the specific type. There was a trend $(\mathrm{p}=0.06)$ for competitive surfers to surf more often during peak UVR as opposed to recreational surfers (50.9\% versus 39.0\%, respectively).

Insert Figure 1 approximately here

Regarding location, NSW participants reported the highest incidence of skin cancers (38.3\%) followed closely by Queensland (37.8\%). Other states included Victoria (8.5\%), followed closely by Western Australia (8.0\%), then South Australia (4.8\%) and Tasmania (0.5\%).

With regard to the total cohort, BCC's were the most frequently (6.8\%) reported NMSC followed by MSCs (1.4\%) and NMSC SCC's (0.6\%). Of note is the number of participants who reported multiple types of skin cancers; BCC and SCC (1.7\%), BCC and SCC and melanoma (0.3\%) and BCC and melanoma (0.2\%). Competitive suffers reported more BCC's (+19.6\%) however, surprisingly there were more MSC reported by recreational surfers (Table 2). There were no significant differences between the type of skin cancer and surfing status 150 (recreational versus competitive). The NMSC BCC was primarily reported in NSW ( $\mathrm{n}=51$ ) followed closely by Queensland (n=47), this was similar to SCCs (NSW, n=17; Queensland, 
152

153

154

155

156

157 Skin cancer by site

158 With respect to the site of the skin cancers (Figure 2), there was a significantly higher incidence

$\mathrm{n}=12$ ). Melanoma skin cancers were most prevalent in Queensland ( $\mathrm{n}=11)$, followed closely by NSW (n=9).

Insert Table 2 approximately here of skin cancers on the face $(\mathrm{p}<0.001)$, back $(\mathrm{p}<0.001)$ and arms $(\mathrm{p}<0.05)$ whereas the feet, thigh and neck had the lowest number of reported skin cancers. Although our cohort of female surf participants is the largest dataset of lifetime prevalence of skin cancer to date, for comparative purposes this study was limited due to the relatively small number ( $n=117$ ) of female participants in comparison to male participants $(n=1231)$. The location of MSC was most commonly reported on the back (27.8\%) followed by the face $(16.3 \%)$ and shoulder and arms $(11.4 \%)$.

Insert Figure 2 approximately here

Key demographical and physiological risk factors

There was a negative correlation between age and time spent surfing with older surfers surfing less hours per week $(\mathrm{p}<0.0001)$ and less weeks per year $(\mathrm{p}<0.005)$. As would be expected, however important to confirm, older surfers had also surfed for more years than their younger counterparts ( $\mathrm{r}=0.73, \mathrm{p}<0.0001)$. Those surfers who surfed more hours per week, tended to also surf more weeks of the year $(\mathrm{p}<0.0001)$. 
174 Surfers reporting a skin cancer had higher body mass index (BMI) $(\mathrm{p}<0.0001)$, older in age $175(p<0.0001)$, and mass $(\mathrm{p}<0.0001)$, though years surfing was identified as the most significant 176 factor $(\mathrm{p}<0.0001)$.

177 There was a significant difference between genders as males reported a higher number of skin 178 cancers versus females $(0.36$ vs. $0.12, \mathrm{p}<0.0001)$. This was however, unsurprising as males 179 also had surfed for more years than females $(\mathrm{p}<0.0001)$ and this was shown to also be related 180 to the number of skin cancers reported.

Competitive surfers were found to have a significantly $(\mathrm{p}<0.001)$ higher proportion of skin cancers than recreational surfers however, competitive surfers had surfed longer $(p<0.0001)$ and were older (36.6 vs. 35.2yrs).

\section{Skin cancer and skin color}

With regard to skin colour, there was a significant $(\mathrm{p}<0.005)$ relationship between the number of skin cancers and lighter skin as fair and medium skin participants reported the highest frequency (43.4\% and 46.7\%, respectively) of NMSCs (86.4\%) and MSCs (13.6\%). However, it should be noted that the limited number of brown $(n=1)$ and black $(n=0)$ skinned participants is not a representative sample.

\section{Discussion}


This study represents the largest survey that has investigated NMSCs and MSC in both recreational and competitive surfers. Our findings are in agreement with the only previously published study (13) which reported a similar (16.3\%) cohort prevalence of skin cancer. Although that study did not report SCC per se, the authors did report a high prevalence (40.8\%) of actinic keratosis which has been shown to give rise to SCCs in 44 to $82 \%$ of cases (19). The prevalence of BCC in our study is less than previously reported (13) (16.3\%) despite our study investigating lifetime prevalence versus incidence.

The risk of skin cancer development has also been investigated in other outdoor recreational and sporting groups and shown to be an independent risk factor for BCC (2). Lichte and colleagues (20) investigated the incidence of skin cancer in mountain guides and reported a similar incidence of BCCs (7.1\%) and a slightly higher incidence of SCCs (1.4\%). The cohort ( $n=283$ ) of adult males only identified 1 MSC. Skin cancer has also been investigated in outdoor farm workers (21), the proportionate MSC incidence (0.18) was found to be higher than urinary bladder cancer (0.59) however, lower than kidney cancer (1.60), liver cancer (4.24), prostate cancer (1.13) and uterine cancer (2.08).

Our data analysis demonstrated that the total number of years surfing was a more significant factor with regard to skin cancer than current surfing activity (hours per week). However, this may be mitigated by the fact that surfers who were older surfed less than their younger counterparts. A consideration is that if older surfers have always surfed less than younger counterparts (an assumption that may not be valid), the extent of skin cancers reported in future may be far higher once the currently younger cohort of surfers have spent an equivalent number of years exposed to UVR whilst surfing. 
221 With regard to the tendency ( $\mathrm{p}>0.05$ ) for less skin cancers on the top of head, face, ears and

222 neck in females, this was possibly attributed to the protective factor of longer hair however, 223 this was not evaluated in the survey and is only speculative.

These findings are in agreement with previous research which have reported a lower incidence of skin cancers in races and ethnicities with darker skin $(22,23)$, as these races and ethnicities have been shown to have a higher melanin content (22). Bradford (24) previously reported in the United States Caucasians had the highest incidence of skin cancers (35-40\%) followed by Hispanics (4-5\%) Asians (2-4\%) and Afro-Americans (1-2\%).

This study also found a lifetime prevalence for melanoma to be $1.4 \%$ within a surfing population whereas a 27 year prevalence of melanoma in Australia was found to be $0.6 \%$ in 2007 (25), comparatively the rate in the USA (26) was reported to be considerably higher (3.8\%) and is expected to rise significantly in the near future (27). This comparison needs to be viewed cautiously as timeframes differ; however as this is the only comparable Australian dataset it highlights the potential threat of melanoma in patients who surf.

Non-melanoma skin cancers are the most common cancer in Australia and the highest in the world (11). These cancers also place a high financial burden on the Australian health care system with an estimated yearly cost of $\$ 700$ million. Given the large proportion of Australians who surf and numbers of reported NMSC and MSC within this cohort, surfers may account for a notable proportion of all skin cancers within Australia. The authors acknowledge that the generalizability of our results is limited to Australian surfers. 
245 With regard to limitations to this study, selection bias may have existed as individuals without

246 internet access would not have had the opportunity to have participated, we attempted to

247 minimize information bias by requiring melanoma and non-melanoma data to only be entered

248 when diagnosed and/or treated by the participants GP or specialist. We believe there was no

249 confounding bias as we did not investigate casual relationships. A further limitation to this

250 study was the exclusion of investigating sun protection strategies which have been shown to

251 be effective in reducing the risk of skin cancer in other outdoor athletes (28).

\section{Conclusions}

254 Surfers have previously been surveyed successfully (29-31) and we believe this study adds 255 insight into the lifetime prevalence of non-melanoma and melanoma skin cancers in the 256 Australian surfing cohort. Although the data obtained was self-report which has recently come under question (32), participants were required to only report skin cancers diagnosed and/or treated by their GP or medical specialist. Given this study's findings with respect to the lifetime prevalence of skin cancer in Australian surfers, GP’s are recommended to rigorously screen their patients who surf as based upon our findings they appear to be at increased risk of developing either a non-melanoma and/or melanoma skin cancer. Screenings are important preventative measures as GP screening examinations has previously been shown to be effective in reducing premature death from skin cancers (5). Furthermore, GP's should also advise patients to utilize multiple sun protection strategies specific to surfing (avoid peak UVR, rashvest, hat and sunscreen $(9,33,34)$ ). Previous investigators (35) have shown that sun safety education programs are effective in changing sun protective behaviours, particularly for nonmelanoma and melanoma skin cancers. 
268 Additionally, lighter skinned surfers with an extensive surfing history appear to a key subgroup 269 at greatest risk for skin cancer. The key high incidence areas of exposure need recognition and 270 strategies to reduce the incidence of skin cancers in these areas would be worthy of 271 consideration (i.e. the face, back and arms). 
274 Acknowledgements

275 The authors wish to thank Surfing Australia’s High Performance Centre, Surfing Australia,

276 Surfing Queensland, SurfRider Foundation, Tracks magazine, Swellnet.com.au, Surfing Life,

277 Fitnessnetwork.com, NBN TV, Nine News, ABC radio (Gold Coast, Sunshine Coast),

278 Sunday Mail, and the Gold Coast Bulletin for assisting in the promotion of this research.

279

280 All authors contributed to the design of the research study, Dr. Furness performed the

281 research, all authors contributed to the statistical analyses and writing of this paper.

282 
283 Disclosure and competing interests

284 None declared

285 
288 1. Stark A. Surfing Australia Annual Report. 2013.

289 2. Moehrle M. Outdoor sports and skin cancer. Clin Dermatol. 2008: 26:12-15.

290 3. Cancer Council of Australia. Skin Cancer Statistics and Issues. 2015.

291 4. Stanton W. Primary prevention of skin cancer in Australia: Report of the Sun Protection 292 Programs Working Party. 1996.

$293 \quad 5 . \quad$ Sladden MJ, Ward JE, Del Mar CB, Lowe JB. Skin cancer screening by Australian family physicians: variation with physician beliefs and geographic locality. Am J Prev Med. 1999: 17:142146.

6. Volkov A, Dobbinson S, Wakefield M, Slevin T. Seven-year trends in sun protection and sunburn among Australian adolescents and adults. Aust N Z J Public Health. 2013: 37:63-69. Tanning' skin cancer prevention mass media campaign and its association with tanning attitudes in New South Wales, Australia. Health Educ Res. 2015.

301 8. Olsen CM, Williams PF, Whiteman DC. Turning the tide? Changes in treatment rates for 302 keratinocyte cancers in Australia 2000 through 2011. J Am Acad Dermatol. 2014: 71:21-26 e21.

303 9. Moehrle M. Outdoor sports and skin cancer. Clin Dermatol. 2008;: 26:12-15.

304 10. Kanavy HE GM. Ultraviolet radiation and melanoma. Semin Cutan Med Surg. 2011: 30:222228.

11. Fransen M, Karahalios A, Sharma N, English DR, Giles GG, Sinclair RD. Non-melanoma skin cancer in Australia. Med J Aust. 2012: 197:565-568.

12. Refshauge A. Cancer Survival and Prevalence in Australia: Period estimates from 1982 to 2010. 2012.

13. Dozier S, Wagner RF, Jr., Black SA, Terracina J. Beachfront screening for skin cancer in Texas gulf coast surfers. South Med J. 1997: 90:55-58.

14. Furness JW, Hing WA, Abbott A, Walsh J, Climstein M. Retrospective analysis of chronic injuries in recreational and competitive surfers: Injury location, type and mechanism. International Journal of Aquatic Research and Education. 2014: 8:228-287.

15. Agency ARPaNS. Radiation Protection. 2014.

16. Gonzaga ER. Role of UV light in photodamage, skin aging, and skin cancer: importance of photoprotection. Am J Clin Dermatol. 2009: 10 (Suppl 1):19-24.

17. Eilers S, Bach DQ, Gaber R, Blatt H, Guevara Y, Nitsche K, et al. Accuracy of self-report in assessing Fitzpatrick skin phototypes I through VI. JAMA dermatology. 2013: 149:1289-1294. 18. Jablonski N. Human Evolutionary Biology. In: Muehlenbein MP, ed. Human Evolutionary Biology. England: Cambridge University Press, 2010: 192-213.

19. Cohen JL. Actinic keratosis treatment as a key component of preventive strategies for nonmelanoma skin cancer. The Journal of Clinical and Aesthetic Dermatology. 2010: 3:39-44. 20. Lichte V, Dennenmoser B, Dietz K, Hafner HM, Schlagenhauff B, Garbe C, et al. Professional risk for skin cancer development in male mountain guides--a cross-sectional study. J Eur Acad Dermatol Venereol. 2010: 24:797-804.

21. Mills PK, Shah P. Cancer incidence in California farm workers, 1988-2010. Am J Ind Med. 2014: 57:737-747.

22. Brenner $M$, Hearing VJ. The protective role of melanin against UV damage in human skin. Photochem Photobiol. 2008: 84:539-549.

23. Control CfD. Skin Cancer Rates by Race and Ethnicity. 2015.

24. Bradford PT. Skin cancer in skin of color. Dermatol Nurs. 2009: 21:170-177, 206; quiz 178.

25. Refshauge A, Kalisch D. Cancer survival prevalence in Australia. 2012.

26. Siegal R, Ma J, Zou Z, Jemal A. Cancer statistics, 2014. 2015. 
56
27. Weir HK, Thompson TD, Soman A, Moller B, Leadbetter S. The past, present, and future of cancer incidence in the United States: 1975 through 2020. Cancer. 2015.

28. Noble-Jerks J, Weatherby RP, Meir R. Self-reported skin cancer protection strategies and location of skin cancer in retired cricketers: a case study from membership of the Emu Cricket Club. J Sci Med Sport. 2006: 9:441-445.

29. Howden J, Danks J, McCluskey P, Gillett M, Ghabrial R. Surfboard-related eye injuries in New South Wales: a 1-year prospective study. Med J Aust. 2014: 201:532-534.

30. Furness J, Hing W, Abbott A, Walsh J, Sheppard JM, Climstein M. Retrospective Analysis of Chronic Injuries in Recreational and Competitive Surfers: Injury Location, Type, and Mechanism. International Journal of Aquatic Research and Education. 2014: 8:277-287.

31. Furness J, Hing W, Walsh J, Abbott A, Sheppard JM, Climstein M. Acute Injuries in Recreational and Competitive Surfers Incidence, Severity, Location, Type, and Mechanism. The American journal of sports medicine. 2015: 43:1246-1254.

32. Holm AS, Wulf HC. Self-reported skin cancer is unreliable. Eur J Epidemiol. 2015: 30:159-162. 33. Glanz K, Mayer JA. Reducing ultraviolet radiation exposure to prevent skin cancer methodology and measurement. Am J Prev Med. 2005: 29:131-142.

34. Saraiya M. Recommendations to prevent skin cancer by reducing exposure to ultraviolet radiation. Am J Prev Med. 2004: 27:467-470.

35. Jinna S, Adams BB. Ultraviolet radiation and the athlete: risk, sun safety, and barriers to implementation of protective strategies. Sports Med. 2013: 43:531-537. 
Table 1. Descriptive statistics for participants (values are mean $( \pm S D)$ ). 95\% Confidence 359 intervals (95\% CI).

\begin{tabular}{|c|c|c|c|c|}
\hline Variable & $\begin{array}{c}\text { Cohort } \\
(n=1,348)\end{array}$ & $\begin{array}{c}\text { Recreational } \\
(n=767)\end{array}$ & $\begin{array}{c}\text { Competitive } \\
(\mathrm{n}=581)\end{array}$ & $P$ value \\
\hline Age (yrs) & $35.84(13.08)$ & $35.2(12.2)$ & $36.7(14.1)$ & .04 \\
\hline Weight (kg) & 78.59 (12.79) & $78.3(11.9)$ & 78.9 (13.7) & NS \\
\hline Height $(\mathrm{cm})$ & $178.16(9.03)$ & $178.6(9.1)$ & $177.7(8.6)$ & NS \\
\hline BMI $\left(\mathrm{kg} / \mathrm{m}^{2}\right)$ & $24.73(3.75)$ & 24.5 (3.3) & $24.9(3.5)$ & NS \\
\hline \multicolumn{5}{|c|}{ Surfing demographics } \\
\hline \multicolumn{5}{|l|}{ Surfing: } \\
\hline - Hours/week & $6.7(5.6)$ & $5.4(4.4)$ & $8.6(6.6)$ & .001 \\
\hline - Weeks/year & $40.5(13.6)$ & $38.0(14.6)$ & $43.8(11.4)$ & .001 \\
\hline - Hours/year & 305.5 (291.2) & 228.7 (214.3) & 406.9 (343.7) & .001 \\
\hline
\end{tabular}

360

361 
363 Table 2. Lifetime incidence of non-melanoma and melanoma skin cancers in participants 364 (number, percentage)

\begin{tabular}{|l|c|c|c|c|}
\hline \multicolumn{1}{|c|}{ Type } & $\begin{array}{c}\text { Cohort } \\
(\mathbf{n = 1 , 3 4 8 )}\end{array}$ & $\begin{array}{c}\text { Recreational } \\
(\mathbf{n = 7 6 7 )}\end{array}$ & $\begin{array}{c}\text { Competitive } \\
(\mathbf{n = 5 8 1})\end{array}$ & P value \\
\hline BCC (n) & 123 & $56(45.5 \%)$ & $67(54.5 \%)$ & NS \\
Melanoma (n) & 25 & $15(60.0 \%)$ & $10(40.0 \%)$ & NS \\
SCC (n) & 36 & $17(47.2 \%)$ & $19(52.8 \%)$ & NS \\
Total (n) & 184 & $88(47.8 \%)$ & $96(52.2 \%)$ & NS \\
\hline
\end{tabular}

365

366 